\title{
The Language Used in the 8th Grade Mathematics Textbook
}

\author{
Mohammad Ahmad Alkhateeb ${ }^{1 *}$ \\ ${ }^{1}$ Hashemite University, JORDAN \\ Received 12 April 2018 - Revised 17 January 2019 - Accepted 24 February 2019
}

\begin{abstract}
This study aimed at identifying the form of the language, which is expressive of the mathematics and mathematics learner in the 8th grade mathematics textbook. The results showed that the mathematics textbook tends to exhibit an absolute, symbolic, mathematics specific image and a negative image of the mathematics learner as just who executes the orders (scribbler), rather than a thinker or engaged in authentic problem solving. Possibly, these two images may explain the difficulties and problems the students encounter while learning mathematics.
\end{abstract}

Keywords: language and mathematics, mathematical symbolism, systemic functional linguistics, mathematics textbook

\section{INTRODUCTION}

Over the few past decades, language became the focus of research in mathematics teaching. Such focus is one of the recent, relative change features in teaching, which main characteristics are represented in a new understanding of the student, and an increase in the complications of the learning contexts, such as those resulting from the cultural and linguistic diversity. Mathematics language was a concern of the mathematics teaching community; many efforts were spent to describe its characteristics, and the ways that may support or cause difficulties for mathematics learners. Development of the relationship between language and mathematics began by considering mathematics as a language exiting by itself, with its own symbols, figures, words and structures. Then, language was seen as a form of communication used in mathematics learning, and a vehicle to build meanings. (Eisenmann, 2007; Morgan, 1996, 2000, 2010; NCTM, 2000; O’Keeffe \& Donoghue, 2015; O'Keeffe \& Donoghue, 2011; Petocz, et al, 2006; Setati, 2002).

Mathematics textbooks are a form of communication used in mathematics learning-teaching. They are important for both the teacher and students as they are the main adopted source in mathematics learning-teaching. In Jordan, for example, the mathematics schoolbooks constitute the major source for teachers and students in the mathematics classes. However, what are the mathematics meanings and ideas, which we could build through our reading of these books? This study is made as an attempt to analyze and explore the functions the language may perform in mathematics learning-teaching. The study proposes some possible interpretations of both the mathematics image and mathematics learner image, which could help in unfolding the difficulties and problems the student may face during mathematics teaching (Morgan, 2010).

The theoretical framework of the study relies on Morgan's (1996) linguistic framework for mathematical texts analysis. Morgan developed a linguistic framework to analyze the mathematics texts depending on the Systematic Functional Linguistics formed by Halliday $(1978,1985)$. It depends on the idea that "any text can realize a number of functions, such as "Interpersonal and Ideational" functions. She based her work upon a substantial idea, i.e. the options. The language enjoys the ability to provide diversified options to use singular, plural, past, present or future tense verbs, first, second and third person pronouns, and words expressing doubt or certainty (O'Keeffe, 2011). Each of these usages has its different connotation from others, which requires us to take care when choosing one option rather than the others. This implicates that the explanation the language reader or listener provides can be affected by this option accordingly (Morgan, 1996). Based on the options idea, the language analysis was made represented by the texts. This is because the analysis is a description of the explanation that could be built from the option the author made versus other interpretations that could be built from other choices he left, which were also available to him (O’Keeffe \& Donoghue, 2015).

(C) 2019 by the authors; licensee Modestum Ltd., UK. This article is an open access article distributed under the terms and conditions of the Creative Commons Attribution License (http://creativecommons.org/licenses/by/4.0/). \mkm7879@yahoo.com (*Correspondence) 


\section{Contribution of this paper to the literature}

- The study provides an analysis of the language used in school mathematics textbooks and suggests some possible explanations for both the mathematics image and the image of the mathematics learner. These explanations may help to identify the difficulties and problems students may face while learning mathematics.

- This study can be used to develop the writing of mathematics textbooks, to consider mathematics as a social act, it is not absolute, and constantly changing, which may be useful in redesigning the curriculum.

- The study of the functionality of the languages in mathematics learning, and the possible language difficulties facing learners require more attention.

Halliday $(1978,1985)$ sees that the mental function expresses the mathematics image and nature: Are mathematics suitable for every time and place? Or else, are they a human activity inseparable from reality (Dozzey, 1992; Ernest, 2004)? Morgan uses the "transitivity" system to identify the mathematics image through the options idea. However, transitivity is present in two aspects: types of processes and types of participants in these processes. Halliday (1985) defined six main types of these processes: physical, mental, relational, behavioral, emotional and verbal processes, the first three processes are the most commonly used.

Choosing a certain process rather than the others may make us build a different explanation of the mathematics image. To identify the physical process in the mathematics texts, we look for the verbs that require carrying out practical activities, such as "I use, I find". On the other hand, we can identify the mental process through the verbs that require mental efforts, while we can identify the relational process through the existence of the mathematics objects. For instance, linking the measurement of the straight angles by measuring two right angles (Morgan, 1996).

More important, when looking at the participants in the mathematical processes, is to define their roles in these processes: are they present through the active voice verbs, or disappear with the passive voice verbs and nominalization? In other words, transforming the mathematics verb into a noun. We can look into the types of the participants in the mathematics process with active voice verbs such as: "I explain that the measurement of $>1$ is equivalent to $>3$. The verb "explain" is in the active voice mode, i.e. the learner shares in learning, and this participation illustrates that mathematics are a human action. Meanwhile, the example "in the triangle $A B C$, its sides AB and AC were divided into four identical parts." The verb "were divided" is in the passive voice mode, which means disappearance of the human existence, as if the two sides of the triangle were divided into four parts without the action of an actor (grammar: subject). This may leave the impression that math is an independent world by itself.

However, the choice of using active voice does not necessarily mean that the image built for mathematics is a human action. To be so, it is inevitable that the actor the verb refers to is the learner, but, when the actor is the symbols of the mathematics terms, it indicates the absolute image of mathematics. For instance, two triangles are congruent if they have three similar, equal sides. Here the congruence is assigned to the actor (the two triangles), as if the two triangles are carrying out the congruence process by themselves. Furthermore, we can identify the mathematics image by nominalization through the example, "the total of the triangle angles is $180^{\circ} . "$

The interpersonal function looks at the role of both the author and the learner in the mathematics text, and the mutual relations between them. Discovery of these relations can be with the first person pronouns (I, we). Their use indicates engagement and participation of the author in the mathematics action, and that the reader is interested in it. This use gives him a kind of responsibility in building the mathematics ideas, such as, "I put the symbol (more than or less than " $<>$ ) in the box", and, "we arrange the similar sides in the two equations under each other." In addition, the use of the second person pronoun (you) indicates a close relation between the book and the learner, causing the learner to engage in studying the mathematics. However, the author draws the attention of the reader with a "certain degree" of power.

Disappearance of the pronouns indicates an official relation between the author and the reader. In some cases, no relation seems between them. For example, "the line connecting between the midpoints of two sides of the triangle is parallel to the third side and half its length. Another example is the use of the imperative mode, such as, "consider, suppose, define", because this mode provides the learner a role to participate in building the mathematics ideas. In this context, Morgan (1996) distinguishes between two types of the imperative mode. The general, such as "let's assume", which looks at the learner as a (thinker), and the special, which looks at the learner as a (scribbler) in the mathematics process, such as "draw a column on the midpoint of a straight line."

The aforementioned interpretations of each of the ideational and interpersonal functions do not necessarily mean that this is the intention of the author. Rather, they are the meanings the reader builds after reading mathematics texts and his interaction with them. Furthermore, both functions are intertwined with each. For instance, looking into the mathematics text, when the actor (subject) is not the human, displays the mathematics 
image as an absolute one in the ideational function. On the other hand, the interpersonal function, with the same indicator, (disappearance of the actor) means that the relationship between the author and the reader is official.

Due to the importance of language and its role in mathematics learning and teaching, many researchers sought to analyze mathematics texts from many aspects and through different tools. Setati (2002) researched the relation between the language and mathematics teaching-learning. Morgan (1996) analyzed the mathematics texts to identify the ideational, interpersonal and textual relations, which the students can build through these texts. Some researchers utilized Morgan's framework (1996) to analyze the mathematics texts, such as Alshuwaikh (2012), Morgan (2001, 2005, and 2006) and Setati (2002). Still other researchers analyzed the mathematics texts to identify the learner's nature (Eisenmann \& Wagner, 2007).

Haggarty and Pepin (2002) attempted to discover the most commonly used mathematics textbooks in three countries, England, France and Germany, to identify the image of mathematics in these countries. They found that the prevalent style of the mathematics image is that it is certain and unquestionable, not affected by the cultural and social contexts where this image takes place, and that the authors appeared as if they were the "knowledge owners". In his analysis of how the concept of "probability" is introduced in the Palestinian mathematics textbooks, Alshuwaikh (2012) found that the concept reveals the human activity in the $4^{\text {th }}$ and $5^{\text {th }}$ classes. Meanwhile, the passive voice verb begins to appear as of the $6^{\text {th }}$ class, and found that the mathematics symbols and terms dominated the probability concept in both the $10^{\text {th }}$ and $12^{\text {th }}$ classes. Eisenmann $(2007)$ analyzed the mathematics text and found a noticeable use of nominalization, and O'Keeffe and Donoghue (2011), in their analysis, found similar results about the use of nominalization in the books of the basic stage mathematics courses.

It seems that the absolute image of mathematics dominates expression about the mathematics ideas. In this concern, Morgan (2001) presented three sentences on a number of female teachers namely: "the rectangle has equal diagonals", "if you measure the lengths of the rectangle, you will find them equal, and "the measure of the rectangle diagonals lengths is always equal." Then she asked them a question about which of the three sentences is the most mathematical? Here, most of them indicated that it was the first sentence, although the three sentences talk about the same information, but their wordings were different. The selection of the first sentence is because it emphasizes the absolute nature of mathematics.

The absolute view of Mathematics also controls many of the students. Crawford, Gordon, Nicholas \& Prosser (1994) found that $73 \%$ of 300 students in one of the Australian universities see that mathematics are abstract, not more than figures, symbols, forms and rules used for problem-solving. This result also appeared in the works of Petocz, et al (2006), O'Keeffe and Donoghue (2015). This absolute view held by numbers of students could be ascribed to many factors, such as the Mathematics image in the Mathematics textbooks; they study, in addition to the Mathematics image held by their teachers, which is apparent through the teaching strategies they use in teaching the Mathematics ideas (Dossey, 1992). Furthermore, the students consider that their task does not go beyond learning (by heart) the information they take during the Mathematics lessons, and then they "download" at the exam time (Crawford, et al, 1994; Moschkovich, 2007). Accordingly, the study attempted to answer the following questions:

- What is the shape of the language that expresses mathematics in the $8^{\text {th }}$ grade mathematics textbook?

- What is the shape of the language that expresses the mathematics learner in the $8^{\text {th }}$ grade mathematics textbook?

\section{METHODOLOGICAL FRAMEWORK}

The study followed the qualitative method, especially ways of analyzing the, texts, because this method can provide an intensive description about a given subject (Creswell, 2012). The lessons were examined and read in a preliminary reading to take a general idea of them, Then the analysis was taken by taking each lesson alone, and the colors were used for shading, based on the indicators of the analysis tool, which is known "color coding", After the shading process, each sentence is interpreted qualitatively, because some of the indicators may be part of a particular interpretation, but when the sentence is understood and interpreted within the context in which it was written, it appears to belong to another interpretation, especially since Morgan (1996) In its linguistic context, she pointed to the importance of knowing the context in which the mathematical text is being analyzed.

After completing the text analysis, deeply standing on the meaning it performs within the language option in which it was written, all words and sentences that have the same meaning are grouped together and placed in their own cursor.

\section{Data Sources}

Part Two of the eighth grade mathematics textbook, which included four units: linear equations with two variables (6 lessons); geometric constructions (4 lessons); triangles (4 lessons), and objects (7 lessons). This book 
constitutes the main source for both the students and teachers, as the Ministry of Education prepares the books and distributes over the schools. The analysis focused on the shape of the language, which expresses mathematics and that which expresses the mathematics learner.

\section{Study Instruments}

Analysis tool developed by Tang, Morgan, and Sfard (2012), which was designed to analyze the mathematics texts and their functions. The tool is divided into two sides, and each side is subdivided into a number of discourse properties which they lead to.

For answering the first question: "What is the shape of the language that expresses mathematics in the $8^{\text {th }}$ grade mathematics textbook?" the researcher considered the following five properties:

- Specialization: to identify the extent of a specialized math language through three indicators: vocabulary used according to the mathematics definitions (vocabulary borrowed from the daily life and used in mathematics contexts); mathematical expressions (vocabularies borrowed from mathematics context), and, mathematical symbols.

- Objectification: to identify whether the text is talking about characteristics of objects or functions through three indicators: shift to nominalization, specialized names that encase the functions, and the relational, material and intellectual functions.

- Alienation: to identify the extent of mathematics alienation through two indicators: presence of two human actors (subjects) in the mathematics functions, and concealing the actor/s (through the active voice where the actor (subject) is a mathematics object, and through the passive voice and shift to nominalization).

- Logical construct: in which we can look into the types of the logical relations presented, and how far such construct is explicitly expressed using connectivity tools.

- State of the mathematical knowledge: to identify how far the text displays the possible decisions and choices during the mathematics activity; and whether mathematics are discovered or invented. This could be achieved through indicators of the alternate (stead) and conditional sentences, and the explicit decisions whether taken or have to be taken, as well as types of the mind/verbal functions.

For answering the second question, "What is the shape of the language that expresses the mathematics learner in the $8^{\text {th }}$ grade mathematics textbook?" the researcher looked in the three following characteristics:

- Effectiveness: to find out the type of activity in which the learner will be engaged, through two indicators of the learner as scribbler and thinker.

- Power: to know where the authority is, whether choices are available, and who makes these choices, through the personal pronouns, and the indicators of the use and certainty.

- Formality: to identify the relation between the author and reader, and whether there is an apparent pedagogical relation between both through the text.

\section{The Validity and Reliability}

The validity of the study instrument was verified by presenting it to specialists in the mathematics curriculum and making necessary adjustments, Because the tool in its original form is written in English, and the researcher translated it into the Arabic language, and the researcher presented it to the reviewers to verify the integrity of the translation and clarity, and verify the suitability of the tool with the Arab culture, the reviewers decided on the validity of the tool and its applicability in the Arab countries. After that, the researcher and his colleague analyzed the language of the mathematics book independently, and explained every sentence specifically. This is because some indicators may apparently belong to a certain explanation, but when the sentence was interpreted and understood through the context it was written, it was found belonging to another explanation. In this concern, Morgan (1996) underlined the importance of knowing the context in which the mathematics text occurs.

Following the text analysis and deep understanding of the meaning it performs within the language choice in which it was written, the researcher collected all the words and sentences that perform the same meaning, and put them within their corresponding indicator. The analysis was continuous and subject to ongoing feedback, and the agreement rate between the two analyzers ranged between (92\%-97\%). 
Table 1. Shape of the Language Expressing Mathematics in the $8^{\text {th }}$ Grade Mathematics Textbook

\begin{tabular}{|c|c|}
\hline $\begin{array}{l}\text { Discourse } \\
\text { Characteristics }\end{array}$ & Result of the Analysis \\
\hline Specialization & $\begin{array}{l}\text { Use of very highly specialized language, which appeared at the level of the vocabularies used according to the } \\
\text { mathematics definitions, mathematical expressions and mathematical symbols. }\end{array}$ \\
\hline Objectification & $\begin{array}{l}\text { - Talk about mathematics objects using nominalization and specific names that encapsulate up the relational } \\
\text { processes to a very wide extent. } \\
\text { - Use of material processes carried out by the student at a very wide scale. } \\
\text { - Use of mental processes much less than the material processes. }\end{array}$ \\
\hline Alienation & $\begin{array}{l}\text { - Use of the human "actors", only through first person pronoun "we" (very few times), but the second person } \\
\text { pronoun "you" (very frequently). There was no use of the first person pronoun "I". } \\
\text { - Concealing the "actor" through: } \\
\text { A- Frequent use of the active voice (where the actor is a mathematics object). } \\
\text { B- Frequent use of the passive voice. } \\
\text { C- Too many shifts to nominalization. }\end{array}$ \\
\hline $\begin{array}{l}\text { Logical } \\
\text { structure }\end{array}$ & $\begin{array}{l}\text { Frequent use of "wa" followed by "fa" (two conjunctions in Arabic meaning and, but with different } \\
\text { connotations); "la (No) that denotes negation; but; i.e.; or; and conditional "if". }\end{array}$ \\
\hline $\begin{array}{l}\text { Mathematical } \\
\text { knowledge } \\
\text { state }\end{array}$ & $\begin{array}{l}\text { - Frequent use of "alternates" and "conditional sentences. } \\
\text { - Presenting the mathematics facts "readymade". } \\
\text { - The language used is decisive and assertive, particularly in generalizations. } \\
\text { - Very much use of the mental/verbal functions. }\end{array}$ \\
\hline
\end{tabular}

\section{RESULTS}

\section{Question 1: What is the Shape of the Language that Expresses Mathematics in the $8^{\text {th }}$ Grade Mathematics Textbook?}

This question was answered through the analysis of five properties: specialization, objectification, alienation, logical structure, and mathematics knowledge condition.

The results showed that mathematics in the $8^{\text {th }}$ grade is characterized by being very highly specialized. It was embodied as a world having its own mathematics objects of logical structure. They also showed that the mathematics facts are certain, accepting no doubt; so that these mathematics facts are approached through the material processes, which make mathematics strange to the students. The passive voice and active voice were used to a very wide scale, particularly in generalizations; with the actor is a mathematics object. Table 1 shows this.

\section{Specialization characteristic}

Generally, there is a wide degree of specialization, as the vocabularies used according to the Mathematics definitions, conventional idiomatical expressions and mathematics symbols, were widely used, Table 2 presents examples of indicators. 
Table 2. Indicators of specialization, Frequency and Examples

\begin{tabular}{lcl}
\hline Indicators & Frequency Examples \\
\hline $\begin{array}{l}\text { Vocabularies used as } \\
\text { per the mathematics } \\
\text { definitions }\end{array}$ & $400 \begin{array}{l}\text { Ordered pair (120), net (21 times), flat (10); plane (12); ball (44); objectify (14); column (24); } \\
\text { tangent (3); side (41); head, base, line, sides (41). }\end{array}$ \\
\hline
\end{tabular}

Circle (2); triangle (2); right angled triangle (1); triangle (42); straight line (8); external angle of
Circle (2); triangle (2); right angled triangle (1); triangle (42); straight line (8); external angle of
the triangle (17); square (6); midline point (3); half the circle (5); center of the circle (2); radius

Mathematical expressions (1); trapezoidal (2); circular segment (2); right cone (26); tri-prism (34); prism quartet (4); linear equation (22); two-variable linear equation (22); equation solving (31); graphic representation of a two-variable linear equation (11); graphical solution of a system of two-variable linear equations (4); solution of a system of two-variable linear equations by compensation (5); solution of a system of two-variable linear equations by deletion (4); intersection of two straights, square of the hypotenuse length, two orthogonal lines.

To express the names of lines (52), for example: two orthogonal lines $A B, C D$.

Te express the equation system (25); example: $A-B+3=0$

$B+A+1=0$

To express $A$ coefficient and $B$ coefficient and the absolute value (12); example: $2 A+4 B=9$

To express names of the points (33), example: $M$ center, $A$ head.

Mathematical

symbols
To express straight lines (33); example: $S$ height; radius; $L$ drawing.

To express theories: Pythagoras theory.

To express size measurement unit (28).

To express area measurement unit (39).

To express the mathematical laws (19).

To express geometrical shapes: triangle (AMB), circle, trapezoidal, square.

The angle (>) (45)

The results showed a very specialized image of mathematics in their three indicators. All the lessons of the mathematics textbook, for the $8^{\text {th }}$ grade, usually begins with vocabularies used according to the mathematics definitions, which are words used in our daily life and in mathematics too. Sometimes, these vocabularies have different meanings from those in the mathematics context, which confuses the students and impedes their learning (Tang, Morgan, \& Sfard, 2012). After that, the mathematics textbook use of special cognitive idiomatic expressions specially coined for the world of mathematics, which the students know in mathematics only, adding more difficulties to the students because they did not know them before (Morgan, 2010). Finally, the previous two indicators are reduced in the form of mathematical symbols. They are not mere written numbers and symbols, as every symbol enfolds a mathematics expression, whether from inside or outside mathematics. This symbol is tied with other mathematics symbols through mathematics relations (O'Keeffe \& Donoghue, 2015; Schleppegrell, 2011).

This specialized image was not affected by the diversity of the topics it dealt with. Presenting mathematics in a specialized image is a reason for certain ambiguity as a result of using words borrowed from "inside" and "outside" mathematics. In addition, this specialized abstract image of mathematics does not match the students' cognitive development, especially basic stage students, who are still in their physical process stage, which Piaget talked about. Therefore, they are unable to think abstractly (AlShwaikh \& Morgan, 2013), which is quite contrary to this abundant use of the mathematics symbols. Even more, certain studies, for instance AlShuwaikh (2012) stated that students in the advanced educational stage could not approach the abstraction level, which Piaget talked about. As for the vocabularies used according to the mathematics definitions, mathematics lessons of the $8^{\text {th }}$ grade included may "borrowed" words and expressions from daily life, that are utilized in the mathematics context. For instance, net, angle, intersection, orthogonal, line, plane, surface, ball, size, area; in addition to the mathematical definitions related to these expressions: acute angle, right angle, obtuse angle and other expressions about the angle.

As for the conventional, idiomatic expressions, the $8^{\text {th }}$ grade mathematics textbook contained a large number of idiomatic expressions $(300 / 1050=29 \%)$. For instance, hypotenuse length square in Pythagoras theory, which is stated in a sentence not easily understood by the reader, as every word contains a mathematics meaning that requires the student retrieve the related experiences (square concept, length concept, hypotenuse concept). Thereafter, the student should connect them with other expressions to understand the mathematics context of the entire sentence. The conventional, idiomatic expressions may enfold many concepts whether from inside or outside the mathematics contexts. Examples of the expressions used in the previous sentence are expressions used in our daily life, such as length, square, hypotenuse. The use of the conventional, idiomatic expressions increases the difficulties the students experience in mathematics learning, in addition to the vocabularies borrowed from our daily life, and used in the mathematics context. (Schleppegrell, 2011).

The results further showed that the mathematics book is "overloaded" with mathematics symbols, which are used for multiple purposes. The issue is not limited to reading the mathematics symbols, but to dive in each of 
Table 3. Indicators of Objectification Characteristic, Frequency and Examples

\begin{tabular}{|c|c|c|}
\hline Indicator & Frequency & Examples \\
\hline $\begin{array}{l}\text { Shift to } \\
\text { nominalization }\end{array}$ & 105 & $\begin{array}{l}\text { Drawn (feminine pronoun, } 7 \text { times); adjacent (4); total (12); drawn (masculine pronoun 14); located } \\
\text { (9); given (5); subtracted (3); adjoining (4); surrounding (3); orthogonal, intersecting, shared (twice } \\
\text { each); prism, parallel (feminine) (5); parallel (masculine) (5); cylinder, aside (3); composed, } \\
\text { objectified, two sides (3); triangles congruence (1). }\end{array}$ \\
\hline $\begin{array}{l}\text { Specialized } \\
\text { nouns } \\
\text { encapsulate } \\
\text { the functions }\end{array}$ & 490 & $\begin{array}{l}\text { System ( } 63 \text { times); intersection (5); solution (101), general picture (5); two-variable linear equation, } \\
\text { circumference (13 each); height (34); length (25); algebraic expression (2); area (89); size/volume } \\
\text { (78); change (8); bisectors, two linear equations with two variables each (19); coefficient (39 times). }\end{array}$ \\
\hline $\begin{array}{l}\text { Relational } \\
\text { functions }\end{array}$ & 40 & $\begin{array}{l}\text { * Solution of two equations system is the intersection point of the two lines resulting from their } \\
\text { graphical representations. } \\
\text { * The two-variable linear equation } A X+B Y+C=0 \text { is an algebraic rule, in which the values of one } \\
\text { variable depend on the other. When we put } Y \text { in the equation in terms of } X \text {, we call } Y \text { subject of the } \\
\text { rule, and the process of writing one variable in terms of the other is called changing the subject of } \\
\text { the rule. } \\
\text { * Size of the right cone is one third the size of the cylinder which shares the cone its base and } \\
\text { height. } \\
\text { * Relation between the length, height and radius is: } L=2 \mathrm{H}=2 \text { radius }{ }^{2} \text {. } \\
\text { * Size of the pyramid is one third the size of the prism in which it has the same base and height. } \\
\text { * The net is a plane object, which could be folded to make an object, it consists of base, face and } \\
\text { heads. } \\
\text { * The shortest distance between two parallel lines equals the length of the column connecting } \\
\text { them. } \\
\text { * Columns drawn from the centers of the triangle sides meet in one point. } \\
\text { * Bisectors of the triangle angles meet in one point. }\end{array}$ \\
\hline Materialism & 423 & $\begin{array}{l}\text { Find (72 times); arrange (20); complete (3): draw (25); solve (62); connect (7); calculate (33); limit } \\
\text { (14); write (20); project(v) (7); create (4); use (4); represent graphically (8); fold (1); express (1); check } \\
\text { (9); bring (7); fill (2); cut (2); locate (1). }\end{array}$ \\
\hline Intellectuality & 45 & $\begin{array}{l}\text { Note (5 times); realize (9); conclude (5); estimate, clarify and discuss (1 each); compare (2); justify } \\
\text { your answer (12); talk (1). }\end{array}$ \\
\hline
\end{tabular}

these symbols to probe the mathematics facts it holds, which, in turn, forms additional difficulty to the students. Some difficulties arise from their weakness in mathematics reading skills, others from their failure to read the mathematics symbols properly (Berger, 2013).

\section{Objectification characteristic}

Five indicators in the mathematics text were explored to identify the mathematics image through objectification; namely: nominalization, specialized nouns that encapsulate the functions, relational functions, physical, and intellectual. In general, the mathematics book objectified mathematics, is if they have their own objects, and used the materialistic functions more and more at the cost of the mental functions. Table 3 presents examples of indicators.

The results showed that the mathematics textbook "works" on objectifying the mathematics as if they were selfexisting work, with its own mathematics objects. Moreover, that such mathematics objects have the ability to carry out the mathematics functions alone without the help of the human. The results also showed that the analyzed units are consistent with the large use of "shift to nominalization" and specialized nouns that encapsulate the functions, which show mathematics as a number of relations in which the mathematics objects carry out the mathematics functions that form the relations on which the mathematics are founded.

As for the relational functions, the results indicated that they were very widely used, reflecting a mathematics image as a self-existing, independent from the human existence. For instance, the example, "Total Square of the two sides' lengths of the right angle triangle is equal to the square length of the hypotenuse." Here the relation between the total lengths of the sides through the "equality" term, without the reference of any human intervention, who found the lengths, squared them, and asserted the equality; a state that embodies mathematics as a universe independent from the human existence. In the matter of the materialistic and mental functions, the book units "agreed" on using the former more than the latter. In spite of the use of the material functions in the mathematics activities, yet, these functions soon disappear when approaching conclusion or generalization. All the practical efforts the students made are "blown out" and transferred into "words" that make the mathematics objects protagonists of the approached generalization. In this concern, the wide use of the relational processes is not confined to the Jordanian mathematics schoolbooks. We find this case in the study of Morgan and Tang (2012), who 
Table 4. Indicators of Alienation, Frequency and Examples

\begin{tabular}{|c|c|c|}
\hline \multirow{2}{*}{\multicolumn{3}{|c|}{$\begin{array}{r}\text { Frequency Examples } \\
\text { Presen }\end{array}$}} \\
\hline & & \\
\hline Subject (actor): I & 0 & None \\
\hline Actor: We & 82 & $\begin{array}{l}\text { We: follow (2 times); call (5); compensate (7); suppose (7); write (3); make (8); solve (11); find (15); } \\
\text { represent (4); add (6); notice (2); e conclude (7); use (2). }\end{array}$ \\
\hline Actor: you & 366 & $\begin{array}{l}\text { You: find (72); arrange (20); complete (3); draw (25); solve (62); connect (7); calculate (33); locate } \\
\text { (14); write (20)'; project (v) (7); create (4); use (4); represent graphically (8); fold (1); express (1); } \\
\text { check (9); bring (7); fill (2); cut (2); show (1); notice (5); make sure (9); conclude (5); estimate- } \\
\text { explain and discuss (1); compare (2); justify your response (12); prove (1); talk (1). }\end{array}$ \\
\hline \multicolumn{3}{|r|}{ Concealing the actor (grammar: subject) } \\
\hline $\begin{array}{l}\text { Active voice } \\
\text { (actor-subject is } \\
\text { a mathematics } \\
\text { object) }\end{array}$ & 20 & $\begin{array}{l}\text { - If the two straight lines became congruent (the subject/actor: is the two lines } A B, C D) \\
\text { - The system has (system is the actor) ( } 3 \text { times) } \\
\text { - Perpendicular to (actor: the straight line AB). } \\
\text { - Intersect with (actor: the two straight lines). } \\
\text { - Congruent to (subject: one of two straight lines (twice). } \\
\text { - Two straight lines result. } \\
\text { - The two straight lines intersected in the point. } \\
\text { - Their heads meet (heads is the actor/subject). } \\
\text { - The figure shows. } \\
\text { - The line divides. } \\
\text { - Two sides became congruent. }\end{array}$ \\
\hline Passive voice. & 20 & $\begin{array}{l}\text { The ordered pair is called (twice); it is said: five doubles of the first subtracted from the second } \\
\text { equals ( } 10 \text { times); to represent the equation, it is graphically represented; these two equations are } \\
\text { called; it is concluded that; called the point; to be bisected ( } 3 \text { times); drawn (2), folded..... etc. }\end{array}$ \\
\hline $\begin{array}{l}\text { Shift to } \\
\text { nominalization }\end{array}$ & 105 & $\begin{array}{l}\text { Drawn (feminine) (7 times); adjacent (4); total (12); drawn (masculine) (14); located at (9); } \\
\text { suggested (5); subtracted (3); adjoining (4); surrounding (3); perpendicular -intersected- parallel } \\
(5 \text { times); joint cylinder (2); joint prism (1); triangles with two congruent sides (3); compound } \\
\text { figure drawn aside (3). }\end{array}$ \\
\hline
\end{tabular}

analyzed the exam papers made in England between 1995 and 2011, and found that the rate of using these processes increased during that period. This is also found in the study of AlSharafa (2015), who analyzed the Palestinian mathematics books.

\section{Alienation}

To identify the image of mathematics through alienation property, the researchers explored two main indicators. First, the existence of two subjects (human actors) in the mathematics functions through the use of first person pronouns (I and we), and second person pronouns. Second, "hiding" the subject through using the active voice (the actor is a mathematics object), and the passive voice and shift to nominalization. In general, the book included revealing and concealing the actors at the same time, where the first person pronoun "we 18\%" was rarely used, but the second person pronoun "you 82\%" was widely used. Both pronouns produce the human subjects (actors) in the mathematics functions, while the first person pronoun "I" totally disappeared. On the other hand, there was too much $(24 \%)$ use to conceal the actor with its three tenses: active voice (actor is mathematics object), passive voice tense and shift to nominalization. Table 4 presents examples of indicators.

The results showed that the predominant feature is keeping mathematics "far" from the students, as the words used in this regard imply that there is a "far" distance between them. In conjunction with alienating mathematics to the eighth graders, indicators are used to reduce the distance between them and mathematics. However, that was not sufficient to eliminate the distance, especially the indicators of "actor's" presence increase when solving the book exercises (Golding, 2010).

Too many indicators of concealing the human doers (subjects of the verb) would take mathematics away from the students, and keep a distance between both. Through hiding the human role, the mathematics functions appear as if they were out of the human control (Morgan \& Tang, 2010). This contributes in rooting the prevailing view of mathematics as an independent, autonomous world where there is no place for human action (AlSharafa, 2015; Morgan, 1996).

\section{Logical structure characteristic}

This trait increases through the use of different conjunctions, which were used in the book, such as "and" , "or", conditional "if", "no", and other conjunctions. The results show the presence of two main traits of the mathematics 
Table 5. Indicators of State of the Mathematics Knowledge Property, Frequency and Examples

\begin{tabular}{|c|c|c|}
\hline Indicator & Freque & Examples \\
\hline Alternates & 4 & $\begin{array}{l}\text { We can use the protractor to find out the measurement of any angle through the following steps.... } \\
\text { The triangle could be called by naming its heads. } \\
\text { We can generalize that every triangle has six outer angles. } \\
\text { It could be said that: measurement of outer angle of the triangle equals the total of the two non } \\
\text { adjacent interior angles. }\end{array}$ \\
\hline $\begin{array}{l}\text { Conditional } \\
\text { Sentences }\end{array}$ & 6 & $\begin{array}{l}\text { * If two lines intersect and one of the intersection angles was right angle, then the other three are } \\
\text { also right angles, and the lines become orthogonal. } \\
\text { * The line falls on the plane if all the points of the line fall on that plane. } \\
\text { * Two straight lines, if you try to extend them as per their straightness from both sides, they will } \\
\text { never meet. } \\
\text { * If you extend the two straight lines, they will meet in one point. } \\
\text { * If two lines intersect, they intersect in one point only. } \\
\text { * If a line crossed two parallel lines, every two alternate angles are equal. }\end{array}$ \\
\hline $\begin{array}{l}\text { Types of the } \\
\text { mental/material } \\
\text { functions }\end{array}$ & 480 & $\begin{array}{l}\text { Mental: Note (5 times); realize (9); conclude (5); estimate, clarify, discuss (1); compare (1); check (3); } \\
\text { justify your answer (12); prove (1); talk (1). } \\
\text { Material: Find (72 times); arrange (20); complete (3); draw (25); solve (62); connect (7); calculate } \\
\text { (33); locate (14); write (20); project (v) (7); create (4); use (4); represent graphically (8); fold (1); } \\
\text { express(1); make sure (9); bring (7); cut (2); locate (1). }\end{array}$ \\
\hline $\begin{array}{l}\text { Available } \\
\text { Choices }\end{array}$ & 4 & $\begin{array}{l}\text { * How many solutions are there for this problem? } \\
\text { * Find (in two ways) measurement of the angle BCD. } \\
\text { * Express (in your language) about what you see. } \\
\text { * Justify your answer by providing examples. }\end{array}$ \\
\hline Language Used & 510 & $\begin{array}{l}\text { A definite, decisive language was used in several places, such as: } \\
\text { * Write every two-variable linear equation in its general shape. } \\
\text { * Rewrite the equation. } \\
\text { * To represent the equation graphically, follow these steps. } \\
\text { * Draw a column on a straight line. } \\
\text { * Project a column on a straight line. } \\
\text { * Move the triangles. }\end{array}$ \\
\hline
\end{tabular}

texts, use of conjunction tools, especially "and", and prominence of the logical relations among the mathematics objects. These two properties display the mathematics texts as logical structures, which components interconnect through logical relations, whether linguistically, through the use of conjunction (and in particular), or mathematically, through the use of specialized words that characterize the mathematics discourse. The mathematics logical structures idea supports the specialty degree of these texts in the schoolbooks, and represent mathematics as a universe having its own mathematics objects with their logical structure.

\section{State of the mathematics knowledge property}

There are five indicators of the mathematics state knowledge trait, namely: alternates (stead in grammar), conditional sentences, types of mental/verbal functions, available choices, and the used language. In general, the researchers found that the mathematics textbook widely used mental/verbal functions and critical language in presenting the mathematics facts. On the other hand, alternates and conditional sentences were less used. Table 5 presents examples of indicators.

Through these results, mathematics appeared as a pool of readymade mathematical facts, presented through a definite, decisive language that does not allow doubt. The mathematics facts, in which the students are allowed the chance to conclude them, are made through following a number of definite steps. The use of the alternates and conditional sentences varied, as in Unit Two, where there was little use, while they were abundantly used in the other units.

\section{Question 2: What is the Shape of the Language that Expresses the Mathematics Learner in the $8^{\text {th }}$ Grade Mathematics Textbook?}

This question was answered through analyzing three properties: doer (grammar; subject), control and formality. The results showed that the language used in the mathematics book for Grade 8 gave the learner a small role in the learning process, where the second person pronouns appeared in lieu of the first person ones, which highlight the role of the learner. However, in both types of pronouns, the role tends to simply implement the orders, but the basic 
Table 6. Indicators of The actor characteristic, Frequency and Examples

\begin{tabular}{|c|c|c|}
\hline Actor (Grammar subject) & Frequency & Examples \\
\hline $\begin{array}{l}\text { Second person pronouns } \\
\text { dominated the } \\
\text { mathematics text, but } \\
\text { mostly were executing the } \\
\text { orders implementer. }\end{array}$ & 60 & $\begin{array}{l}\text { Student as an order implementer (scribbler): } \\
\text { First Person Pronouns: } \\
\text { (We): call (8 times); symbol (5); say (5); can (5); draw (twice)... } \\
\text { Second Person Pronouns: } \\
\text { (You): find (7 times); arrange (20); complete (3); draw (25); solve (7); calculate (33); } \\
\text { define (14); write (20); project "verb" (7); create (4); use (4); write (9); represent } \\
\text { graphically (8); fold (1); express (1); make sure (9); bring (7); fill (2); cut (2); locate (1)... }\end{array}$ \\
\hline & 82 & $\begin{array}{l}\text { Student as a thinker: } \\
\text { First person pronouns: } \\
\text { (We): notice (twice); conclude, locate, calculate and find. } \\
\text { Second person pronouns: }\end{array}$ \\
\hline & 50 & $\begin{array}{l}\text { Mental: (You): notice ( } 5 \text { times); ensure }(9) \text {; conclude (5); estimate, clarify, discuss (1); } \\
\text { compare (2); realize (3); justify your answer (12); prove (1); talk (1). }\end{array}$ \\
\hline
\end{tabular}

Table 7. Indicators of Control characteristic, Frequency and Examples

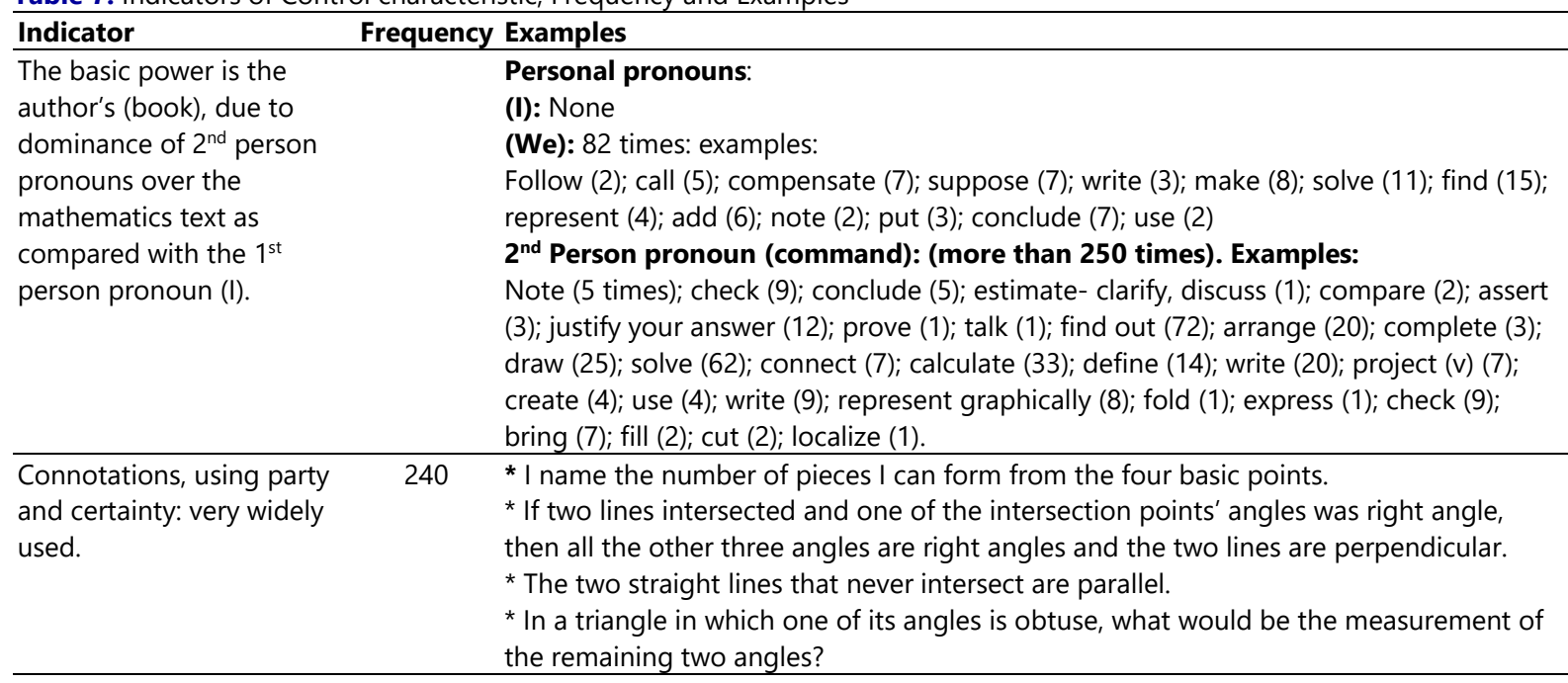

power was for the author (the book). Still, the pedagogical relation between the learner and the author appeared at low degree.

\section{The actor characteristic}

In general, it seemed that the second person pronouns dominated the mathematics text, but these pronouns tended to implement the order. Table 6 illustrates the two indicators of the actor characteristic; Table 6 presents examples of indicators.

\section{Control characteristic}

Generally, the basic power was clearly the author's (the book), due to the dominance of the second person pronouns over the mathematics text, as compared with the first person pronoun (I). The pronouns the book used tended to make students implement orders rather than to think. As for the connotations of the modality for the control and certainty, they were widely used. Table 7 shows examples of the two indicators of the control property; Table 7 presents examples of indicators.

\section{Formality}

In general, there is a relationship between the author and the learner, due to the use of the first person pronoun (we) to a medium extent (36\%). The passive voice was "much $64 \%$ " used, especially when it comes to generalizations. Finally, it seems that the nature of the text is specialized because of the too frequent use of the specialized mathematics symbols and vocabulary. Table 8 shows the indicators of the three characteristics of formality; Table 8 presents examples of indicators. 
Table 8. Indicators of Control characteristic, Frequency and Examples

\begin{tabular}{|c|c|c|}
\hline Indicator & Frequency & Examples \\
\hline $\begin{array}{l}\text { - There is a relation between the } \\
\text { author and the student through } \\
\text { the use of the first person pronoun } \\
\text { (we) to a medium extent }\end{array}$ & 82 & $\begin{array}{l}\text { Use of the pronoun "We": } \\
\text { (We): call (8 times); say (5); can (5), note (twice); it leads us to; shall know; put; } \\
\text { discover; take out; described; conclude; define; use; find out ... etc. }\end{array}$ \\
\hline $\begin{array}{l}\text { - Passive voice was used to a wide } \\
\text { extent, especially in } \\
\text { generalizations. }\end{array}$ & 145 & $\begin{array}{l}\text { - Active voice (actor-subject is a mathematics object) (20) } \\
\text { - Passive voice (20). } \\
\text { - Shift to nominalization (105) }\end{array}$ \\
\hline
\end{tabular}

These results of the characteristic indicators of the language expressing the mathematics learner, represented by the eighth grade mathematics schoolbook, show that the learner was given a role; still, to a little extent. The learner's role begins decreasing so that the book becomes the basic role through the increase of second person pronouns. Nonetheless, the student still builds the mathematics thoughts through implementing the orders required by the book, to achieve the mathematics generalizations.

In the few times when the main role was given to the learner, they also tended to implement the orders. The student is assigned the task of thinking using the second person pronouns. However, what changes is the nature of the verbs used, which are more likely to think than to implement orders. The researcher noticed that they are, apparently, more likely tend to thinking, but they are only present in solved examples; thence they are used in exercises that simulate the solved examples through the lesson presentation. This eliminates the thinking process, and pushes the student to repeat the solution method already used in the solved example. This also appeared in the analysis of Alshwaikh (2015), when he indicated that the exercises come after presenting the theory and submitting its solved examples. Thus, the exercises appear as if asking the students to recur the way the examples were solved, with the same words, although the question uses the word "prove", which is among the indicators that introduce the students as thinkers.

As for the control, it was only the schoolbooks', which appeared using pronouns, so that the first person pronoun (I) disappears, and (We) is used at a low degree. As for the using party, and certainty connotations, which are the second indicator of the control characteristics, they were very widely used in the eighth grade mathematics book. This book is characterized by too many and long lessons, and the frequent use of the first person pronoun (We), particularly in the second unit, in a manner that decreases the formality between the author and learner. On the other hand, use of the passive voice is too much increasing, as the nature of the text is "very tightly specialized". The formal relation may create barriers between the students and mathematics learning, who may see mathematics as a very special and strange universe. As such, they fear taking it because it is a difficult, complicated subject, full of specialized mathematics vocabularies and symbols, which cause disturbance for them. This result was also found in (Dossey, 1992; Morgan, 1996).

The results of the three characteristics of the discourse show that they tend to display a negative image of the mathematics learner as a mere scribbler. Giving the learner the basic role in the learning process indicates the learner's engagement in the mathematics action (Morgan, 1996, 2006); and that students have an active role in building the mathematics ideas, which is in compliance of the modern theories (structural and social structure) (Oliver, 1989). But it seems that students are not sufficiently active in the learning process, due to the use of indicators that describe them as mere scribblers; they have not space for free thinking; not given different choices to follow the way they see fit to approach mathematics facts. All the book lessons have one planned, drawn way by the book designers, and students should only follow this way to reach the mathematics facts. Lack of the learners' presence as thinkers indicates that the traditional, behavioral view of the students still exists. In this way, learners are only vessels wherein information is placed and stored, which will be retrieved at the exam time, which implies that learners have no role in building their own knowledge (Moschkovich, 2010).

\section{CONCLUSIONS}

It is clear through the study that mathematics appears at first as the subject stems from the human existence, Then this presence begins to decrease gradually, The stereotype of mathematics is replaced by absolute and symbolic, And it is a self-world, based on independent groups of relationships between mathematical objects. As it can be seen that the mathematics learner appear as passive recipients and just executing orders, Based on the results of the study, attention should be given to the definition Teachers should identify the different views about the mathematics image and mathematics learner's image, which enables them make students perceive this different image, even if the schoolbooks were not developed.

Since the analysis results showed that the mathematics books tend to present students as mere scribblers, teachers could be qualified to produce students able to think. This also provides students chances to be mathematicians who build mathematics ideas through encouraging them to engage in written activities and tasks. 
Such activities do not focus on making students display their comprehension of the mathematics content only, but also of the thinking mechanism, they performed to show how did they approach the solution.

Developing the mathematics schoolbooks in a manner that shows the other image of mathematics as a human activity, and students as engaged in the learning process actively, so they will be given space for thinking more than being mere "scribblers", and followers of predetermined steps.

Conducting research works that focus on exploring the relationship between the language and their uses choices with the students' believes. There are other forms of communication including images and gestures, which are also of a vital role that can not be ignored or minimized in mathematics learning-teaching. This calls the necessity to explore these two aspects and find out their impact on mathematics and mathematics learner's image.

\section{REFERENCES}

Alsharafa, H. (2015). Analyzing Geometry in the Palestinian Mathematics Textbooks Using Linguistic Approach (Unpublished MA Thesis), Birzeit University.

Alshuwaikh, J. (2012). Mathematics, Language and Communication. A research paper presented at the conference: The Arabic Language in Palestinian Universities between Reality and Tom, Birzeit University, Palestine.

Alshwaikh, J, \& Morgan, C. (2013). Analysing the Palestinian school mathematics textbooks: A muktimodal (multisemiotic) perspective. Proceedings of the British Society for Research into Learning Mathematics, 33(2), 7075.

Alshwaikh, J. (2015). Image-writing relations in Arabic mathematical textbooks. In G. Rijlaarsdam (Series Ed.) \& A. Archer \& E. Breuer (Eds.), Studies in writing: (pp. 117-135). Leiden. Brill. https://doi.org/10.1163/9789004297197_007

Berger, M. (2013). Examining mathematical discourse to understand in-service teachers' mathematical activities. Pythagoras, 34(1), 1-10. https:/ / doi.org/10.4102/ pythagoras.v34i1.197

Crawford, K., Gordon, S., Nicholas, J. \& Prosser, M. (1994). Conceptions of Mathematics and how it is learned: The perspectives of student entering University. Learning and Instruction, 4(4), 331-345. https:/ / doi.org/10.1016/0959-4752(94)90005-1

Creswell, J. (2012). Educational Research: Planning, Conducting, and valuating Quantitative and Qualitative Research (2nd Ed.). New Jersey, USA: Pearson.

Dossey, J. (1992). The nature of mathematics: Its role and its influence. Handbook of research on mathematics teaching and learning, Macmillan, New York, 39-48.

Eisenmann, B. (2007). From intended curriculum to written curriculum: examining the "voice" of a mathematics textbook. Journal for Research in Mathematics Education, 38(4), 344-369.

Eisenmann, B., \& Wagner, D. (2007). A framework for the uncovering the way a textbook may position the mathematics learner. For the Learning of Mathematics, 27(2), 8-14.

Ernest, P. (2004). What is the philosophy of mathematics education? 10 th International Congress of Mathematical Education, Copenhagen. Retrieved from http:/ / www.icmeorganisers.dk/dg04/contribution/ernest.pdf

Golding, M. (2010). Pupils learning mathematics. In S. Johnston-Wilder, P. Johnston- Wilder, D. Pimm and J. Westell (Eds.). Learning to teach mathematics in the secondary school (pp. 44-64).

Haggarty, L., \& Pepin. B. (2002). An investigation of mathematics textbooks and their us in English, French and German classrooms: Who gets an opportunity to learn what? British Educational Research Journal, 28(4), 567590. https:/ / doi.org/10.1080/0141192022000005832

Halliday, M. (1985). An Introduction to Functional Grammar. London: Edward Arnold.

Halliday, M. (1978). Language as Social Semiotic: The Social Interpretation of Language and Meaning. London: Edward Arnold.

Morgan, C. (1996). Writing mathematically: The discourse of investigation. London: Flamer Press.

Morgan, C. (2000). Language in use in mathematics classrooms: Developing approaches to a research domain (Book review). Educational Studies in Mathematics, 21, 93-99. https:/ / doi.org/10.1023/ A:1003891809328

Morgan, C. (2001). Mathematics and human activity: Representation in mathematical writing. In C. Morgan \& K. Jones (Eds), Research in Mathematics Education Volume 3: Papers of the British Society for Research into Learning Mathematics (pp.169- 182). London: British Society for Research into Learning Mathematics.

Morgan, C. (2005). Words, definitions and concepts in discourses of mathematics, teaching and Learning. Language and Education, 19(2), 103-117. https:/ / doi.org/10.1080/09500780508668666 
Morgan, C. (2006). What does social semiotics have to offer mathematics education research? Educational Studies in Mathematics, 61(1/2), 219-245. https:// doi.org/10.1007/s10649-006-5477-x

Morgan, C. (2010). Communicating mathematically. In S. Johnston- Wilder, P. Johnston-Wilder, D. Pimm \& J. Westwell (Eds.), learning to teach mathematics in the secondary school (pp. 119-132). London: Routledge.

Morgan, C., \& Tang, S. (2012). Studying changes in school mathematics over time the lens of examinations: The case of student positiong. In T.Y. Tso (Ed.), Procedings of the 36th Conference of the international group for the Psychology of Mathematics Education (Vol.3, pp. 241-248). Taipei, Taiwan: PME

Moschkovich, J. (2007). Beyond words to mathematical content: Assessing English learners in the mathematics classroom. In A. Schoenfeld (Ed.), Assessing Mathematical Proficiency (345-352). New York, NY: Cambridge University Press. https:/ / doi.org/10.1017/CBO9780511755378.027

Moschkovich, J. (2010). Language and mathematics education: Multiple perspectives and directions for research. Charlotte, NC: Information Age Publishing.

National Council of Teachers of Mathematics. (2000). Principles and standards for school mathematics. Reston, VA: NCTM.

O'Keeffe, L. \& Donoghue, J. (2011), A Review of Secondary School Textbooks for Project Maths, Technical Report, University of Limerick, NCE-MSTL.

O'Keeffe, L. \& Donoghue, J. (2015), a role for language analysis in mathematics textbook analysis. International Journal of Science and Mathematics Education. 13(3), 605-630. https:/ / doi.org/10.1007/s10763-013-9463-3

O'Keeffe, L. (2011). An Investigation into the Nature of Mathematics Textbooks at Junior Cycle and their Role in Mathematics Education, Unpublished, University of Limerick.

Petocz, P., Wood, L., Smith, G., Mather, G., Harding, A., Engelbrecht, J., Houston, K. Hillel, J. \& Perrett. G. (2006). Undergraduate student's conceptions of Mathematics: An international study. International Journal of Science and Mathematics Education. 5(3), 439-459. https:/ / doi.org/10.1007/s10763-006-9059-2

Schleppegrell, M. (2011). Language in mathematics teaching and learning: A research review. In J. Moschkovich (Ed.), Language and mathematics education: Multiple perspectives and directions for research (pp. 73-112). Charlotte, NC: Information Age Publishing.

Setati, M. (2002), Researching Mathematics Education and Language in Multilingual South Africa. The Mathematics Educator. 12(2), 6-20.

Tang, S., Morgan, C., \& Sfard, A. (2012). Investigating the evolution of school mathematics through the lens of examinations: developing an analytical framework. Paper presented at the 12th International Congress on Mathematical Education, Topic Study Group 28 on Language and Mathematics, Seoul, Korea.

\section{http://www.ejmste.com}

